\title{
Responsabilidade civil do ortodontista
}

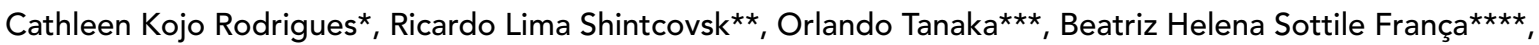

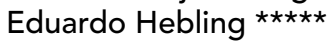

\begin{abstract}
Resumo
O objetivo da terapia ortodôntica é a correção de problemas dentários e esqueléticos, visando resultados estéticos e funcionais estáveis. Tais objetivos, naturalmente, aumentam a expectativa do paciente quanto aos resultados e geram dúvidas nos ortodontistas em diversas situações clínicas. Este trabalho teve como objetivo esclarecer as principais dúvidas dos ortodontistas quanto à sua responsabilidade pelos casos tratados, seus direitos e deveres na relação profissional/paciente e na prevenção de ações judiciais. A comunicação com o paciente e/ou responsável, com a descrição do plano, riscos, benefícios e custos do tratamento, bem como a elaboração, anuência e guarda da documentação ortodôntica, são fundamentais na prevenção de litígios judiciais. A conduta profissional deve ser embasada nos princípios da ética e da moral.
\end{abstract}

Palavras-chave: Odontologia Legal. Responsabilidade civil. Ortodontia.

\section{INTRODUÇÃO}

A relação profissional/paciente é um dos fatores de sucesso da prática odontológica. $\mathrm{O}$ cirurgião dentista utiliza os conhecimentos científicos e os meios colocados à sua disposição para recompor a saúde de seus pacientes. Para tanto, este é contratado com base na confiança que inspira nos mesmos ou em seus responsáveis. Além disso, também responde pelos resultados de seus atos quando ficar demonstrado que houve negligência, imprudência ou imperícia no seu atuar ${ }^{15}$.

$\mathrm{Na}$ Ortodontia, a expectativa do paciente quanto aos resultados é grande, podendo gerar conflitos na relação profissional/paciente, dúvidas quanto à conduta a seguir pelos ortodontistas em diversas situações clínicas e até mesmo resultar em litígios judiciais. É bastante evidente a falta de conhecimento dos ortodontistas quanto à responsabilidade pelos casos tratados, bem como qual a melhor forma de se prevenir de ações judiciais impetradas pelos seus pacientes ${ }^{15}$.

A atuação do cirurgião-dentista exige conhecimentos legais que transcendem aqueles fornecidos pela graduação, pela natureza de constante alterações nas leis e normas que regem esta profissão. A prestação de serviços em Ortodontia, especificamente, gera direitos e deveres para ambas as partes envolvidas: ortodontista e paciente ${ }^{27}$.

Desta forma, o presente trabalho baseia-se numa revisão de literatura a respeito da responsabilidade civil do ortodontista, tendo como objetivo esclarecer as principais dúvidas destes quanto aos direitos e deveres na relação profissional/paciente e na prevenção de ações judiciais.

\footnotetext{
* Advogada e Mestranda em Saúde Coletiva da Faculdade de Odontologia de Piracicaba - UNICAMP.

** Cirurgião-dentista.

Professora Doutora em Odontologia Legal e Deontologia da Pontifícia Universidade Católica do Paraná (PUC-PR), Universidade Tuiuti do Paraná (UTP) e Universidade Federal do Paraná (UFPR).

**** Professor Doutor em Ortodontia da Pontifícia Universidade Católica do Paraná (PUC-PR).

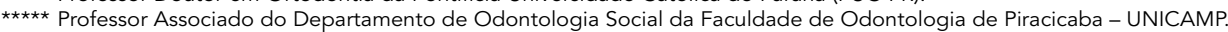




\section{DESENVOLVIMENTO}

\section{Natureza da obrigação do ortodontista}

O ponto de partida para se compreender a responsabilidade civil do ortodontista é estabelecer o tipo de obrigação que tal profissional assume quando da prestação dos seus serviços, ou seja, se é uma obrigação de meio ou de resultado.

A obrigação de meio, para o Direito Civil, é quando o devedor promete empregar os seus conhecimentos, meios e técnicas para a obtenção de um determinado resultado, sem, no entanto, responsabilizar-se por ele. É o caso, por exemplo, dos médicos que não se obrigam a curar, mas a tratar bem dos enfermos, fazendo uso de seus conhecimentos científicos. Se a obrigação assumida por esses profissionais fosse de resultado, seriam eles responsabilizados civilmente se a causa não fosse ganha ou se o paciente viesse a falecer ${ }^{18,21}$.

Quando a obrigação é de resultado, o obrigado ou devedor dele se exonera quando o fim prometido é alcançado. Não o sendo, é considerado inadimplente, devendo responder pelos prejuízos decorrentes do insucesso. Exemplo é a obrigação assumida pelo cirurgião-plástico, por realizar trabalho de natureza estética, assumindo o risco do resultado ${ }^{10,22}$.

O embasamento legal para a responsabilização do devedor que assume a obrigação de resultado é o artigo 313 do Código Civil Brasileiro que define a obrigação de dar coisa certa nos seguintes termos: "o credor de coisa certa não pode ser obrigado a receber outra, ainda que mais valiosa". E o inciso I, do art. 35 do Código de Defesa do Consumidor ${ }^{3,14}$ que prevê que o consumidor pode "exigir o cumprimento forçado da obrigação, nos termos da oferta, apresentação ou publicidade"19.

Ressalte-se que há casos na lei em que o ofertante não se vincula à proposta, conforme as circunstâncias e imprevistos ou por culpa de terceiros (art. 393 do Código Civil Brasileiro) ${ }^{3}$.

A maioria dos autores do Direito Civil afirma que, em regra, a obrigação do cirurgião-dentista é de resultado, com base no argumento de que os processos odontológicos são mais regulares e as terapêuticas mais definidas, o que possibilita ao profissional comprometer-se com o resultado ${ }^{8,11,12,17}$.

No entanto, o tratamento ortodôntico não comporta somente o trabalho de ordem estética, pois freqüentemente engloba a reabilitação funcional da oclusão (CFO Resolução 22/2001, art. 34, Seção III) ${ }^{7}$.

O ortodontista ao realizar o tratamento ortodôntico assume a obrigação do resultado ao prometer a estética, e a obrigação de meio ao buscar resultado estético aplicando toda a sua perícia e todo o seu zelo durante o tratamento ${ }^{5,11}$.

A obrigação do ortodontista deve ser analisada caso a caso, pois existem tratamentos em que os resultados são previsiveis, bem como existem tratamentos difíceis e de resultados imprevisiveis ${ }^{17,26}$.

A questão da obrigação do ortodontista se reflete no ônus da prova em caso de processos judiciais, sendo que nas obrigações de resultado, se o fim almejado não é obtido, a vítima não poderá provar a culpa do profissional para obter indenização, incumbirá ao cirurgião-dentista destruir a presunção de sua culpa e comprovar que teve conduta diligente, mas, mesmo assim, sobreveio evento imprevisível ${ }^{28}$.

Portanto, o ortodontista pode atrair pacientes divulgando e promovendo resultados estéticos, conforme previsto nos artigos 32 e 33 do Código de Ética Odontológica, de 20/05/2003, mas sempre mencionando os meios pelos quais chegará ao resultado e obrigando-se somente naquilo que efetivamente seja capacitado ${ }^{26}$.

\section{Obrigatoriedade da realização de Contrato de Prestação de Serviços}

Compreendida a questão da natureza da obrigação assumida pelo ortodontista e suas implicações legais, surge outra questão relevante: a da obrigatoriedade ou não do contrato de tratamento ortodôntico. E ainda, se adotado o contrato, qual é a validade de suas cláusulas?

A relação profissional/paciente é regulada pelo 
Direito Civil na parte que trata de prestação de serviço. O artigo 594 do Código Civil prevê que "toda espécie de serviço ou trabalho lícito, material ou imaterial, pode ser contratada mediante retribuição" .

Além disso, a Lei 8078/90, (Código de Defesa do Consumidor), art. $3^{\circ}$ enquadra o cirurgião-dentista como "fornecedor" de serviços. Essa lei não obriga que as prestações de serviço se constituam através de contrato escrito, sendo válido o trabalho realizado mediante acordo verbal, mas que tem natureza contratual, no qual, especificamente, o ortodontista assume a obrigação de esforçar-se e aplicar a técnica correta para o resultado programado $^{16,24}$.

O contrato de prestação de serviços, no entanto, é regido pelo princípio da obrigatoriedade da convenção, pelo qual as estipulações feitas no contrato deverão ser fielmente cumpridas (pacta sunt servanda), sob pena de execução patrimonial contra o inadimplente ${ }^{29}$.

O referido contrato deve ser firmado entre as partes, de forma livre e sendo válido como norma de direito entre as partes, autorizando o contratante a pedir na justiça o cumprimento da obrigação por ventura não cumprida pelo contratado $^{2}$.

Contrato válido é aquele que obedece aos requisitos do artigo 104 do Código Civil Brasileiro (CCB), quais sejam: possuir agente capaz, objeto lícito e forma prescrita ou não de defesa em lei ${ }^{25,29}$. Sendo válido, o contrato é inatingível, a menos que ambas as partes o rescindam voluntariamente ou haja a escusa, por caso fortuito ou força maior (Art. 393, parágrafo único do CCB).

A adoção do contrato pelo ortodontista, como já foi dito, é opcional, mas se adotado, deve conter cláusulas válidas que efetivamente indiquem os passos do tratamento ortodôntico, pois tais cláusulas formam lei entre as partes ${ }^{29}$.

O Código de Defesa do Consumidor, Lei 8078/90, no artigo 51, prevê um rol exemplificando, entre outras a do inciso IV, que condena cláu- sulas que "estabeleçam obrigações consideradas inóquas, abusivas, que coloquem o consumidor em desvantagem exagerada, ou sejam incompatíveis com a boa-fé ou a eqüidade"16.

Em seu artigo 46, esse Código dispõe que "os contratos que regulam as relações de consumo não obrigarão os consumidores se não lhes for dada a oportunidade de tomar conhecimento prévio de seu conteúdo, ou se os respectivos instrumentos forem redigidos de modo a dificultar a compreensão de seu sentido e alcance". Em seu artigo 47, ainda prevê que "as cláusulas contratuais serão interpretadas de maneira mais favorável ao consumidor" ${ }^{\prime \prime, 16}$.

Assim, o contrato firmado pelo ortodontista deve conter o objeto do contrato descrito de forma precisa, explicando qual é o tipo de serviço a ser prestado, e o modo pelos quais o tratamento se desenvolverá e, principalmente, mencionar que o tratamento é um meio para se obter o resultado estético mais favorável possível, tendo em vista a estrutura e o arco dentário do caso específico a ser tratado ${ }^{2}$.

\section{Responsabilidade durante e pós-tratamento}

Um ponto bastante polêmico e gerador de conflitos entre ortodontista e paciente diz respeito ao tempo de duração do tratamento e periodo de responsabilidade civil do ortodontista pós-tratamento ${ }^{20,26}$.

O tratamento ortodôntico não é um padrão estanque porque cada caso requer análise individual. Assim, o ortodontista pode fazer uma estimativa do prazo de duração do tratamento e do prazo para o atendimento do paciente pós-tratamento, conforme o caso específico ${ }^{23}$.

A estimativa do prazo para o tratamento ortodôntico deve considerar as circunstâncias de cada caso, como o aumento ou diminuição da tração para o posicionamento dos dentes, e as conseqüências resultantes do tratamento, tais como os desvios de mordida, mau posicionamento de arcada e dores nas articulações, os quais podem aumentar 
ou diminuir o prazo de tratamento inicialmente estipulado ${ }^{23}$.

Considerando que a determinação de prazo para o tratamento ortodôntico é convenção particular entre o ortodontista e paciente e que a lei prevê a liberdade de contratação e a prevalência da vontade na celebração dos atos civis, não há previsão legal para o prazo de reabilitação do tratamento ortodôntico.

Todavia, uma vez que o ortodontista estabeleça um prazo para o tratamento ortodôntico, este deve ser respeitado, considerando, como já foi dito, as circunstâncias de cada caso.

Quanto ao período de atendimento ao paciente após o tratamento ortodôntico, geralmente tal atendimento é prolongado até que se atinja a estabilidade do arco dentário, se tudo correr conforme a previsão inicial do tratamento.

A responsabilidade civil do ortodontista tornase mais evidente no término do tratamento e principalmente se os resultados não são satisfatórios ou ocorreram seqüelas como desvios de mordida, dentes abalados, encurtamento de raízes, dores nas articulações, enfim, quando sobrevêm danos ao paciente decorrentes de falhas cometidas pelo ortodontista.

Mesmo finalizado o tratamento com os resultados planejados, as seqüelas danosas são consideradas como causas de imputabilidade de responsabilidade do ortodontista. A responsabilidade civil decorrente dos danos causados em tratamentos ortodônticos mal sucedidos, de modo geral, é prevista no art. 186 do Código Civil Brasileiro que prevê, nos seguintes termos "aquele que por ação ou omissão voluntária, negligência ou imprudência, violar o direito, causar prejuízo a outrem, ainda que exclusivamente moral, comete ato ilícito". E ainda do artigo 927 que diz: "aquele que, por ato ilícito (arts. 186 e 187), causar dano a outrem, fica obrigado a repará-lo".

Esses conceitos são importantes, tanto que os Tribunais já têm decidido da seguinte forma:

"EMENTA: Responsabilidade civil - Ato ilícito
- intervenção cirúrgica realizada por profissional sem orientação comprovada de especialista em Ortodontia - Defeito de oclusão ou articulação e diastemas decorrentes - imprudência caracterizada - obrigação de pagar as despesas de novo tratamento a que se submeteu a vítima - Ação procedente. (TJSP. Rel. Des. Gomes Corrêa - ap. 29.867-1 - 1 ${ }^{\mathrm{a}}$. Câm. - j. 06.09.1983- vu) ${ }^{23}$.

Assim, a responsabilidade civil do ortodontista decorre dos danos causados pelo tratamento ortodôntico no qual se comprovem que o ortodontista agiu com imperícia ou imprudência ou negligência no exercício da profissão.

O artigo 951 do Código Civil Brasileiro é preceito legal específico da responsabilidade civil dos ortodontistas, prevendo que o disposto nos arts. 948, 949 e 950 aplica-se ainda no caso de indenização devida por "aquele que, no exercício de atividade profissional, por negligência, imprudência ou imperícia, causar a morte do paciente, agravarlhe o mal, causar-lhe lesão ou inabilitá-lo para o trabalho" ${ }^{30}$.

A reparação em Direito Civil, nos casos de danos ou prejuízos decorrentes de tratamentos ortodônticos, é feita por meio da indenização em dinheiro ou pelo pagamento das despesas de tratamento do paciente atingido por seqüelas decorrentes das falhas cometidas pelo ortodontista tenha tido.

INDENIZAÇÃO - Responsabilidade civil - dentista- ortodontista - Execução insatisfatória dos serviços, obrigando o autor a refazê-los, bem como a pagá-los novamente a outro profissional - Condenação do réu à devolução da quantia recebida - Embargos rejeitados (JTJ-Lex 159/205) ${ }^{23}$.

Responsabilidade Civil. Cirurgião-dentista. Tratamento incompleto. Causação de danos ao cliente. Obrigação ressarcitória inarredável, inclusive no referente a danos morais. Quantificação exacerbada destes. Redução. Apelo provido em parte. (TJSC - Ap. Cív. 97.011438-9 - Capital Rel. Des. Trindade dos Santos) ${ }^{23}$.

O artigo 949 do Código Civil prevê que: 
"no caso de lesão ou outra ofensa à saúde, o ofensor indenizará o ofendido das despesas do tratamento e dos lucros cessantes até o fim da convalescença, além de algum outro prejuízo que o ofendido prove haver sofrido".

A recidiva no tratamento ortodôntico é fato que, por causas diversas, faz com que os dentes retornem à posição que tinham antes do tratamento ortodôntico.

Para o direito civil a recidiva é o retorno à situação anterior à formação do contrato de prestação de serviços do ortodontista, ou seja, há o desfazimento do contrato escrito ou tácito entre o ortodontista e o paciente ${ }^{2}$.

No caso, há o desfazimento do acordo de tratamento ortodôntico pela recidiva. É considerado como se o paciente não tivesse iniciado e concluído o tratamento ortodôntico, e se o paciente não recebeu a prestação do serviço, o ortodontista não deveria ter recebido a contra-partida através do pagamento efetuado pelo paciente ${ }^{29}$.

Ocorre que, na prática, nenhum ortodontista devolve o pagamento no caso de recidiva do tratamento ortodôntico. Cerca de 70\% dos ortodontistas, nos casos de recidiva, propõem retratamento ortodôntico $^{13}$.

A questão para o Direito resolve-se com a devolução do preço, ou seja, do pagamento efetuado pelo paciente ou a substituição do serviço por outro que seja eficaz. Nos casos em que o paciente optar por utilizar os serviços de outro profissional, o ortodontista que causou a recidiva ou os danos deve arcar com este novo tratamento, conforme interpretação analógica do artigo 18 , parágrafo $1^{\circ}$ do Código de Defesa do Consumidor que prevê que o consumidor pode exigir:

"I - a substituição do produto por outro da mesma espécie, em perfeitas condições de uso;

II - a restituição imediata da quantia paga, monetariamente atualizada, sem prejuízo de eventuais perdas e danos..."

INDENIZAÇÃO - Responsabilidade civil - dentista - Execução insatisfatória dos serviços, obrigando o autor a refazê-los, bem como a pagálos novamente a outro profissional - Condenação do réu na devolução da quantia recebida - Embargos rejeitados - (TJSP - EI 183.274-2 - 169 CC. J. 22.02.1994. Rel. Des. Hermes Pinotti) ${ }^{23}$.

A recidiva do tratamento ortodôntico envolve, também, a ética profissional, o Código de Ética Odontológica, Resolução no 42, de 20/05/2003, do Conselho Federal de Odontologia, no art. $5^{\circ}$, inc. XII, prevê que "é um dever do profissional da Odontologia assumir responsabilidade pelos atos praticados".

\section{Prazo para o paciente interpor ação judicial contra o ortodontista}

O prazo para o ingresso de ação judicial do paciente contra o ortodontista pretendendo a reparação de danos é de 3 (três) anos, entendendo que o início do prazo começa a contar da constatação do dano, art. 205, V do CCB. Essa é a interpretação analógica com o artigo 27 do Código de Defesa do Consumidor.

Quanto à defesa do ortodontista frente às ações judiciais, o paciente baseia-se no ato do serviço mal prestado pelo ortodontista, no dano causado por este ato, na relação de causalidade entre o dano ou omissão e no dano e a culpa ${ }^{23}$.

A responsabilidade subjetiva é adotada pelo Direito Brasileiro no que se refere aos profissionais liberais, inclusive o Código de Defesa do Consumidor, que adota a responsabilidade objetiva, excepciona a respeito quando se trata de profissional liberal (art. 14, par. $4^{\circ}$ ) e, como já foi dito, pressupõe três elementos: dano, culpa e nexo de causalidade. Culpa, em síntese, é o desvio de um modelo ideal de conduta, isto implica na avaliação dos fatores subjetivos que conduziram o ortodontista à prática do ato lesivo ${ }^{18}$.

O profissional da Odontologia deve atuar de acordo com o cuidado, a perícia e os conhecimentos compatíveis que seriam razoáveis esperar de um cirurgião-dentista prudente, naquelas mesmas circunstâncias. Deve, pois, o ortodontista conhecer e fazer 
tudo aquilo ou quanto um outro diligente cirurgiãodentista faria se estivesse nas mesmas condições.

Quando se trata de responsabilidade subjetiva, o cirurgião-dentista pode eximir-se do dever de indenizar, desde que demonstre ausência de culpa ou ruptura do nexo de causalidade.

A prova de ausência de culpa, na responsabilidade civil do cirurgião-dentista, implica na demonstração de que o dano era imprevisível ou inevitável. Livra-se da responsabilidade civil aquele que prova que agiu de acordo com os cânones da Odontologia em conduta irrepreensível. Mesmo ocorrendo o dano, não se pode afirmar que o dano tenha sido causado pela conduta do profissional.

Outra defesa para o cirurgião-dentista é observar se o paciente adotou comportamento que quebrou o nexo de causalidade, como a inobservância de recomendações e cuidados durante $o$ tratamento que ligariam as conseqüências danosas à conduta do profissional.

Em regra geral, demonstrar que o cirurgião dentista atuou com imperícia, imprudência e negligência e que daí resultou dano ao paciente é atividade que na prática suscita dificuldade ${ }^{23}$.

Uma forma de se comprovar a falta de colaboração ou conduta indisciplinada do paciente é se fazer a anotação destas no prontuário clínico do mesmo e salientar a este ou a seu responsável legal, no caso de menores, colhendo sua assinatura de que está ciente destas observações. Pode-se também fazer uso de Carta Registrada indicando os comportamentos não-cooperativos ao tratamento e suas conseqüências.

A melhor forma de se fazer esta comprovação é elaborar e manter a documentação do paciente, com radiografias e modelos realizados durante e após o tratamento e a solicitação de anuência do paciente, ou de seu responsável legal, em caso de menores, a todas as comunicações ou prescrições realizadas.

Vale lembrar que a exceção do art. 14, par. $4^{\circ}$ do Código de Defesa do Consumidor é válida somente para o profissional liberal e, portanto, não se aplica às sociedades profissionais liberais da área de saúde (pessoas jurídicas), as quais se submetem ao sistema objetivo de responsabilidade civil, ou seja, o agente responde pelos danos sofridos pela vítima, ainda que não tenha agido com culpa ${ }^{6,23}$.

O artigo $6^{\circ}$, VII do Código de Defesa do Consumidor traz mais uma exceção importante no que se refere ao ônus da prova em lides propostas por pacientes.

Este artigo possibilita ao julgador a inversão do ônus da prova, quando for verossímil a alegação do consumidor ou quando for ele hipossuficiente, segundo as regras ordinárias da experiência. De tal sorte, que nesses casos o dentista demandado deverá comprovar que não agiu culposamente.

\section{DISCUSSÃO}

As normas que regem a responsabilidade civil do ortodontista esclarecem que a relação ortodontista-paciente ocorre pela formação de um contrato entre as partes, seja ele escrito ou verbal. A inexecução contratual faltosa de sua obrigação, faz com que o ortodontista esteja sujeito aos preceitos da responsabilidade legal, a qual está assentada na culpa, assim é preciso analisar se este agiu com ou sem culpa ${ }^{18}$.

A culpa possui três modalidades: a imperícia, a imprudência e a negligência.

Imperícia é a falta de habilidade para praticar determinados atos que exigem certo conhecimento ${ }^{17}$. É a ignorância, incompetência, desconhecimento, inexperiência, inabilidade, imaestria na arte ou profissão ${ }^{31}$.

Imprudência, por sua vez, consiste na precipitação, na falta de previsão, em contradição com as normas do procedimento sensato ${ }^{17}$. É a afoiteza no agir, o desprezo das cautelas que cada qual deve tomar com seus atos ${ }^{9}$.

Negligência é a omissão daquilo que razoavelmente se faz, ajustadas as condições emergentes às considerações que regem a conduta normal dos negócios humanos. É a inobservância das normas que nos ordenam a agir com atenção, com capa- 
cidade, solicitude e discernimento. Relaciona-se, no mais das vezes, com a desídia, ocorrendo por omissão de precauções às quais o agente deveria se obrigar ${ }^{9}$.

Assim, age com culpa o cirurgião-dentista que foi imprudente, negligente ou imperito e responde segundo a regra geral da responsabilidade civil do artigo 927, Código Civil: "aquele que por ação ou omissão voluntária, violar direito ou causar prejuízo a outrem, fica obrigado a reparar o dano".

O artigo 951 CC ainda determina: "o disposto nos arts. 948, 949 e 950 aplica-se ainda no caso de indenização devida por aquele que, no exercício de atividade profissional, por negligência, imprudência ou imperícia, causar a morte do paciente, agravar-lhe o mal, causar-lhe lesão, ou inabilitá-lo para o trabalho".

Clóvis Beviláqua ${ }^{1}$ argumenta que a responsabilidade dos profissionais citados "funda-se na culpa, e a disposição tem por fim afastar a escusa, que poderiam pretender invocar, de ser o dano um acidente no exercício de sua profissão; o Direito exige que esses profissionais exerçam sua arte segundo os preceitos que ela estabelece e com as cautelas e precauções necessárias.

O artigo 14, da Lei $n^{\circ}$ 8078/90 CDC, parágrafo $4^{\circ}$ afirma que: "a responsabilidade pessoal dos profissionais liberais será apurada mediante a verificação de culpa".

Por profissional liberal há que se entender o prestador de serviço do tipo solitário, ou seja, aquele que faz do seu conhecimento a sua ferramenta de sobrevivência. É o médico, o engenheiro, o arquiteto, o advogado, o dentista ${ }^{18}$.

O profissional de Odontologia em sã consciência jamais pretende causar mal ao paciente. No entanto, o cirurgião-dentista não deve desprezar a hipótese de que danos imprevisíveis podem advir de suas atividades.

Não é necessário possuir formação jurídica para saber que o resultado desfavorável em ações judiciais causaria perdas financeiras, abalos no conceito e auto-estima dos ortodontistas.
Portanto, esse trabalho serve de alerta aos profissionais da Ortodontia para lembrar-lhes que a Odontologia não é uma ciência exata, não existem arcos a serem corrigidos, mas sim pacientes, sendo estes pessoas acometidas de problemas de má oclusão que nem sempre requerem o mesmo tipo de tratamento.

Todas as decisões clínicas e científicas requerem avaliações prévias. Estas irão variar de acordo com as mais diferentes situações, com a capacitação e com a formação pessoal do profissional. Como os valores morais e opiniões sobre situações vividas na área odontológica são muito díspares, pode-se verificar a dissonância entre as soluções potencialmente sugeridas para a resolução de conflitos ${ }^{27}$.

O conhecimento dos preceitos legais que regem a profissão do cirurgião-dentista proporciona maior segurança em sua atuação. A comunicação com o paciente e/ou responsáveis, com a descrição do plano, riscos, benefícios e custos do tratamento, bem como a elaboração, anuência e guarda da documentação ortodôntica são fundamentais na prevenção de litígios judiciais. A conduta profissional deve ser embasada nos princípios da ética e da moral. 


\title{
Civil responsibility of orthodontist
}

\begin{abstract}
The aim of orthodontic treatment is to correct dental and osseous disorders in order to get aesthetic and functional stable results. This aim, naturally, improves the patient's expectatives over the results and produces misgiving in the orthodontists in different clinical situations. The aim of the present study was to clarify the principal doubts of the orthodontists' responsibilities about the cases treated by them, their rights and obligations in the relationship of profissional/patient, and in prevention of the lawsuit. The patient and/or responsible communication, the description of plan, risks, benefits and custs of the treatment, as well the consent and guard of orthodontics documentation were fundamental to prevent lawsuit. The professional dealing shall be embased in the ethical and moral principles.
\end{abstract}

Key words: Legal Dentistry. Civil responsibility. Orthodontist.

\section{REFERÊNCIAS}

1. BEVILÁQUA, C. Código Civil dos Estados Unidos do Brasil. Rio de Janeiro: Sociedade Cultural, 1979. v. 4

2. BITTAR, C. A. Responsabilidade civil médica, odontológica e hospitalar. São Paulo: Saraiva, 1991.

3. BRASIL. Novo Código Civil: Lei no. 10.406/2002. Diário Oficial da União, Brasília, DF, 10 jan. 2002

4. BRASIL. Lei no 8.0878/90. Código de Defesa do Consumidor. Diário Oficial da União, Brasília, DF, 11 mar. 1991.

5. CALVIELLI, I. P. Natureza da obrigação assumida pelo C.D. no contrato de locação de serviços odontológicos. Rev Assoc Paul Cir Dent, São Paulo, v. 50, n. 4, p. 325-318, jul./ago. 1996.

6. CAVALI, R. C. A responsabilidade civil do profissional liberal da área de saúde no direito brasileiro. Rev Assoc Bras Odontol, São Paulo, n. 17, p. 6, fev./mar. 2003.

7. CONSELHO FEDERAL DE ODONTOLOGIA. Resolução CFO 22/2001. Diário Oficial da União, DF, 27 dez. 2001.

8. COUTINHO, L. M. Responsabilidade ética, penal e civil do médico. Brasília: Brasília Jurídica, 1997. 289 p.

9. DIAS, J. A. Da responsabilidade civil. 10. ed. Rio de Janeiro: Forense, 1995. p. 121-124

10. DINIZ, M. H. Curso de direito civil. 7. ed. São Paulo: Saraiva, 1998. v. 7. p. 431-432.

11. DINIZ, Maria Helena. Curso de direito civil. 2. ed. São Paulo: Saraiva, 2000. p. 184-185.

12. DOWER, N. G. Curso moderno de direito civil. 2. ed. São Paulo: Melpa, 1997. 333 p.

13. FERNANDES, F.; CARDOZO, H. F. Responsabilidade civil do cirurgião dentista: pós-tratamento ortodôntico. Disponível em: < www.ibemol.com.br>. Acesso em: 24 abr. 2001.

14. FILOMENO, J. G. B. Manual de direitos do consumidor. 5. ed. São Paulo: Atlas, 2001. 580 p.

15. FRANÇA, B. H. S.; RIBAS, M. O.; LIMA, A. A. S. Orientações legais aos ortodontistas. Rev Dental Press Ortodon Ortop Facial, Maringá, v. 2, n. 2, p. 25-31, abr./mai. 2002

16. GAMA, H. Z. Direitos do consumidor: Código de Defesa do Consumidor. Lei $n^{\circ} 8.078 / 90$ de 11.09 .90 entrada em vigor 11.03.91 referenciado e legislação correlata. 4. ed. São Paulo: Forense, 1999. $353 \mathrm{p}$

17. GIOSTRI, H. T. Erro médico à luz da jurisprudência comentada. Curitiba: Juruá, 2000.

18. GONÇALVES, C. A. Responsabilidade civil. 5. ed. São Paulo: Saraiva, 1994. $587 \mathrm{p}$

19. KFOURI NETO, M. Culpa médica e ônus da prova. São Paulo: Revista dos Tribunais, 2002. 527p.

20. LAURANCE, J. Ethical considerations regarding the timing of orthodontic treatment. Am J Orthod Dentofacial Orthop, St. Louis, v. 113, no. 1, p. 85-90, Jan. 1998.
21. MATIELO, F. Z. Responsabilidade civil do médico. Porto Alegre: Sagra Luzzatto, 1998. $259 \mathrm{p}$

22. MONTEIRO, W. B. Curso de direito civil. 30. ed. São Paulo: Saraiva, 1999. v. 4

23. NERY JUNIOR, N.; NERY, R. M. A. Código civil anotado. 2. ed. São Paulo: Revista dos Tribunais, 2003. 1790 p.

24. OLIVEIRA, J. Comentários do Código de Defesa do Consumidor. São Paulo: Saraiva, 1991. 403 p.

25. PEREIRA, C. M. S. Instituições de direito civil. 13. ed. Rio de Janeiro: Forense, 1999. v. 3

26. PEDROTTI, I. A. Responsabilidade civil. 2. ed. São Paulo: Universitária de Direito, 1995. v. 1

27. PUPPIN, A. A. C.; PAIANO, G. A.; PIAZZA, J. L; TORRIANI, M. A Ético versus legal: implicações na prática clínica. Rev ABO Nac, São Paulo, v. 8, n. 1, p. 38-41, fev./mar. 2000.

28. QUEIROGA, A. E. Responsabilidade civil e o novo código civil. São Paulo: Renovar, 2003. 323 p.

29. RODRIGUES, S. Direito civil dos contratos e das declarações unilaterais de vontade 28 ed. São Paulo: Saraiva, 2002 v 3.

30. VENOSA, S. S. Direito civil. 5. ed. São Paulo: Atlas Jurídico, 2005. v. 4.

ZAMPIERI JR., S.; MOREIRA, A. Erro médico: semiologia e implicações legais. JBM, Rio de Janeiro, v. 69, n. 1, p. 116-120, julho 1995.

Endereço para Correspondência

Cathleen Kojo Rodrigues

Rua Brigadeiro Franco, 1.766, Apto. 112

CEP.: 80.420-200 - Curitiba/PR

E-mail: cathleen@netpar.com.br 